\title{
Biólogos e outros entes na caatinga: etnografia e endemismo em contextos de relações transespecíficas ${ }^{1}$
}

\author{
Biólogos y otros entes en la caatinga: etnografía y endemismo en \\ contextos de relaciones transespecíficas
}

\begin{abstract}
Biologists and other beings in the caatinga: ethnography and endemism in contexts of trans-specific relations
\end{abstract}

Elizeu Pinheiro da Cruz ${ }^{2}$

\begin{abstract}
Resumo
A diversidade biológica do Brasil é composta por seis biomas: amazônia, cerrado, caatinga, mata atlântica, pantanal e pampa. Dentre eles, a caatinga é o único que os biólogos reconhecem como exclusivamente brasileiro. Tal distinção é produzida por plantas, animais e biólogos em contextos de pesquisa. Frente a isto, este artigo apresenta apontamentos relacionados aos trabalhos de biólogos e uma planta que, vinculados em relações transespecíficas, circunscrevem territórios nas ciências biológicas a partir da descrição de um endemismo da caatinga, Arrojadoa marylanae, espécie de cacto ameaçada de extinção. Ele é um desdobramento de uma etnografia desenvolvida entre os anos 2011 e 2016 em laboratórios de ciências biológicas da Universidade Estadual do Sudoeste da Bahia que deslocou o foco do estritamente humano para as relações entre biólogos, plantas e outros entes. Trata-se de uma experiência de pesquisa multidisciplinar situada entre as ciências biológicas e as ciências sociais. Ao focar em contextos práticos de relações transespecíficas entre biólogos e plantas, foi possível entender a taxonomia como construção relacional, classificação e história.
\end{abstract}

Palavras-Chave: Biólogos; biodiversidade; Cactácea; diferença; territórios.

\section{Resumen}

La diversidad biológica de Brasil está compuesta por seis biomas: amazonia, cerrado, caatinga, mata atlántica, pantanal y pampa. Entre ellos, la caatinga es el único que los biólogos reconocen como exclusivamente brasileño. Esta distinción es producida por plantas, animales y biólogos en contextos de investigación. Frente a esto, este artículo presenta apuntes relacionados a los trabajos de biólogos y una planta que, vinculados en relaciones transespecíficas, circunscriben territorios en las ciencias biológicas a partir de la descripción de un endemismo de la caatinga, Arrojadoa marylanae, especie de cactus amenazada de extinción. Él es un desdoblamiento de una etnografía desarrollada entre los años 2011 y 2016 en laboratorios de ciencias biológicas de la Universidad Estatal

\footnotetext{
${ }^{1}$ Versão revisada de parte da minha tese de doutorado, desenvolvida junto ao Programa de Pós-Graduação em Ciências Sociais da Universidade Federal da Bahia e intitulada "Plantas, animais, biólogos e outros entes na caatinga: notas etnográficas em mundos de areia”, orientada pelas professoras Dr. ${ }^{a}$ Iara Maria de Almeida Souza e Dr. ${ }^{a}$ Núbia Regina Moreira. Para a elaboração deste artigo, trabalhei com materiais analíticos produzidos entre os biólogos que pesquisam na e $a$ caatinga com apoio da Universidade do Estado da Bahia (UNEB) e da Fundação de Amparo à Pesquisa do Estado de Bahia (FAPESB).

${ }^{2}$ Doutor em Ciências Sociais; docente do Curso de Ciências Biológicas e do Programa de Pós-Graduação em Ensino, Linguagem e Sociedade (PPGELS) do Departamento de Ciências Humanas da Universidade do Estado da Bahia; Campus VI, Caetité, Bahia, Brasil; elizeuprof@gmail.com
} 
del Sudoeste de Bahía que desplazó el foco de lo estrictamente humano hacia las relaciones entre biólogos, plantas y otros entes. Se trata de una experiencia de investigación multidisciplinaria situada entre las ciencias biológicas y las ciencias sociales. Al enfocarse en contextos prácticos de relaciones transespecíficas entre biólogos y plantas, fue posible entender la taxonomía como construcción relacional, clasificación e historia.

Palabras clave: Biólogos; biodiversidad; Cactácea; diferencia; territorios.

\begin{abstract}
The biological diversity of Brazil is composed of six biomes: amazon, cerrado, caatinga, Atlantic forest, wetlands and pampa. The caatinga is the only one that biologists recognize as exclusively Brazilian among them. Such distinction is produced by plants, animals and biologists in research contexts. Considering this, this article presents notes related to the works of biologists and a plant which linked in trans-specific relations and which circumscribe territories in the biological sciences from the description of an endemism of the caatinga, Arrojadoa marylanae, a species of cactus threatened with extinction. It is an unfolding of an ethnography which was developed between the years 2011 and 2016 in biological sciences labs of the Southwest of Bahia State University that shifted the focus from the strictly human to the relations between biologists, plants and other entities. It is a multidisciplinary research experience which is located between the biological sciences and the social sciences. By focusing on practical contexts of trans-specific relationships between biologists and plants, it was possible to understand taxonomy as relational construction, classification and history.
\end{abstract}

KEYWORDS: Biologists; biodiversity; Cactaceae; difference; territories

\title{
1. Introdução
}

Umbuzeiros, mandacarus, formigas, abelhas, cabras, juazeiros, pássaros, flores, lagoas, rios, umidades, chuvas, serras, sóis, barrancos e muitos outros entes puderam ser vistos por quem andou pela região sudoeste do Estado da Bahia no início de janeiro de 2016 e podem ser vistos em muitos momentos do constante redesenhar deste território que, em determinadas frações, é “classificado" como caatinga ${ }^{3}$, bioma ${ }^{4}$ exclusivamente brasileiro (SCHOBER, 2002). Relacionando com esses entes em encontros etnográficos de interlocução, estabelecidos entre os anos de 2011 e 2016, partilhei olhares, escutas e descrições em efeitos de sentidos situados entre as ciências biológicas e as ciências sociais.

O trabalho de campo a que se refere este texto foi desenvolvido em territórios nomeados, simultaneamente, de semiárido, caatinga, sertão e sudoeste da Bahia. Meus interlocutores usavam essas nominações para fazer referências aos territórios onde atuavam, coletando e

\footnotetext{
${ }^{3}$ Toda vez que o termo caatinga aparecer no singular, estarei referindo-me aos discursos específicos sobre este bioma, como aqueles produzidos pelas ciências biológicas e pelo estado brasileiro. Quando o termo aparecer no plural, será uma negativa a ideia do território pronto (feito!) para, influenciado por Ingold (2015), entendê-lo como relação, movimento e descrição (conhecimento).

${ }^{4}$ Bioma é um conceito que transita pelas ciências biológicas e mobiliza alguns apontamentos relacionados às muitas vidas animais e vegetais que se relacionam com fatores físico-químicos (como temperatura, luz, radiação solar, dentre outros) de forma peculiar em um determinado território.
} 
descrevendo plantas e animais. Começo este texto tomando o sudoeste do Estado da Bahia como ponto de partida por dois motivos: é um híbrido constituído por semiárido, caatinga e sertão e é uma categoria de território que nomeia a instituição à qual vinculam-se os biólogos com quem estabeleci interlocução, a Universidade Estadual do Sudoeste da Bahia (UESB) ${ }^{5}$.

$\mathrm{Na}$ antropologia, há um crescente interesse analítico pelas relações entre humanos e não humanos (LATOUR, 2012), sobretudo pelas relações entre humanos e animais não humanos (SOUZA, 2017; PERROTA, 2017; SEGATA, 2015; SÜSSEKIND, 2014; LAW; MOL, 2009) que concebe estes últimos como entidades ativas e não apenas pelos aspectos utilitaristas concernentes às interações. Interessei também pelas relações entre humanos e não humanos, pelo papel de plantas e animais na constituição de coletivos nas ciências biológicas, e rastreei cactos, abelhas, vespas, roedores, biólogos e outros entes em pesquisas voltadas para a descrição da biodiversidade. No percurso do trabalho de campo, interroguei: sudoeste da Bahia, caatinga, semiárido, sertão, endemismos ${ }^{6}$, biomas, plantas, animais e biólogos, como estes entes agregam-se para produzir taxonomias? Neste artigo, trato apenas de apontamentos relacionados aos trabalhos de biólogos e plantas (cactáceas ${ }^{7}$ ) que, vinculados em relações transespecíficas, circunscrevem territórios nas ciências biológicas. Transespecificidade aqui é compreendida em consonância com Sá (2013, p. 249):

[...] um dispositivo propício à reflexão e ao tensionamento de determinada condição de espécie, em que mediante um encontro entre espécies distintas (um evento interespecífico), as próprias condições de existência e seus limites de contorno entram em relação. A transformação interespecífica, ou simplesmente a transespecificidade, se dá quando o resultado deste realinhamento relacional é algo diferente daquilo que previamente reconheceríamos como comportamentos, ações, hábitos, performances coligadas aos corpos e características de cada espécie. A transespecificidade é, portanto, um fenômeno anti-atlas.

Taxonomias de plantas e animais são descrições que inventariam os seres que habitam um determinado local. O trabalho prático de uma taxonomia nas ciências biológicas inicia-se com a realização de uma expedição para conhecimento e coleta de espécimes de animais e plantas que se revelam ao olhar especializado do biólogo. Espécimes coletadas que apresentam

\footnotetext{
${ }^{5}$ A UESB possui três campi localizados em três municípios da Bahia: Itapetinga, Jequié e Vitória da Conquista. Os biólogos que participaram da pesquisa retomada por este texto estão vinculados ao Curso de Ciências Biológicas do Campus de Vitória da Conquista, Bahia.

6 Os biólogos chamam de endemismo o fenômeno em que uma espécie ou grupo taxonômico ocorre exclusivamente em uma determinada região geográfica.

${ }^{7}$ Biólogos usam, quando escrevem, a grafia em latim, "Cactaceae". No entanto, opto por manter a grafia "cactácea" para manter correspondência com a forma como eles dizem quando falam dos espécimes da Família Cactaceae.
} 
formas corporais díssonas frente aos táxons já catalogados são direcionados para estudos que poderão culminar com a descrição de uma " "nova' espécie” ou “"novo' grupo” taxonômico.

O botânico sai em expedição à busca de plantas e o zoólogo, de animais. E, mesmo nesta divisão, há subdivisões: o zoólogo-ornitólogo, por exemplo, se afetará pelas aves com maior intensidade do que por um mamífero. E, assim, ao serem percebidas em experiências singulares de ornitólogos com aves, de mirmecólogos com formigas, de orquidófilos com orquídeas, dentre outros, territórios como caatinga fazem-se visíveis. Em outras palavras, os territórios são circunscritos às descrições de animais e plantas, que são também definidos por meio deles. Formulações feitas pelos meus interlocutores, como "periquito da caatinga" e "planta da mata atlântica", indicam, por meio das locuções adjetivas, vinculações entre territórios e animais ou plantas.

O trabalho de campo é central na prática de biólogos que pesquisam diversidade e ocorrência de plantas, animais e outros entes em um determinado território. Por isso, é instigante incidir sobre práticas singulares em contextos específicos de pesquisadores como ornitólogos, mirmecólogos e orquidófilos, buscando escapar dos possíveis reducionismos da definição "biólogo" e das simplificações produzidas pelas generalizações sobre os territórios por eles visitados e descritos para investir algum esforço de entendimento mais atento as suas experiências transespecíficas. Modos específicos de ver (BERGER, 2000) plantas e animais são, intimamente, relacionados a modos distintos de trabalho, conhecimento e nominação de um mesmo território nas descrições dos biólogos. Dito de outro modo: seria um equívoco supor que os biólogos possuem uma identidade única e fixa. Então, por entender que os seus contextos de ação são bons para identificarmos as suas distinções, interesso-me pelas práticas que elaboram, constantemente, descrições de plantas, animais e territórios. Trata-se de pensar a identificação dos biólogos em seus contextos de interação nos quais relacionam com os significantes não humanos dos seus trabalhos de campo. Geertz (2017), ao refletir sobre a cultura de um povo, ensinou que, para dissolver as opacidades, produzidas, a meu ver, por generalizações como biólogo, é necessário colocar os interlocutores no quadro das suas banalidades. Portanto, para descrever biólogos e ciências biológicas em construção, decidi segui-los caatingas, sertões e semiáridos afora (LATOUR, 2011). 


\section{Engajamento etnográfico}

Assumi os territórios caatinga, sertão, semiárido e região sudoeste da Bahia como campo de pesquisa em 2011, momento em que iniciei a produção de dados para uma pesquisa de mestrado que almejou compreender quais e como eram mobilizados os saberes dos biólogos que atuavam no Curso de Licenciatura em Ciências Biológicas da Universidade Estadual do Sudoeste da Bahia. As condições de produção da pesquisa de mestrado e o curto tempo para conclusão do texto impediram um percurso mais prolongado no campo e, por conseguinte, a produção dos materiais ${ }^{8}$ analíticos. No doutoramento em Ciências Sociais, concluído em 2018, continuei transitando pelos territórios que compõem o campo etnográfico a que se refere este texto e trabalhando analiticamente com o corpus produzido para a pesquisa de mestrado. Produzi novos dados por meio de entrevista, análise de documento e observação participante e operei o deslocamento do olhar para o centro onde vivo (caatinga, sertão e semiárido) e para o centro onde estudei e atuo (as ciências biológicas), problematizando territórios e ciências biológicas como constituições naturais, coletivos sociais e efeitos de discursos, como redes em tramas de naturezas-culturas (LATOUR, 2013). Em suma, mobilizo aqui os materiais analíticos produzidos entre os anos de 2011 e 2016 que produzem um campo etnográfico textual que, enquanto produção inventiva (STRATHERN, 2014) do campo caatinga-semiárido-sertão (o sudoeste da Bahia), atualiza a minha estadia e convida os meus leitores a nele se enredarem.

Daqui por diante, este artigo está dividido em cinco partes. A fim de apontar alguns significados sobre caatinga, sertão e semiárido, categorias que compõem o híbrido região sudoeste da Bahia, apresento, na primeira parte, algumas formulações sobre territórios. $\mathrm{Na}$ segunda, descrevo apontamentos relacionados à emergência de uma cactácea da caatinga. Refaço a expedição à Serra Escura, onde vive a planta endêmica descrita pelos biólogos com quem estabeleci interlocução, na terceira parte. Na quarta parte, ao considerar os endemismos como indicadores de áreas de proteção da biodiversidade, problematizo a dicotomia localglobal. E, por fim, na quinta parte, articulo algumas intepretações horizontalmente distribuídas por este texto.

\footnotetext{
${ }^{8}$ Diferente dos analistas de discurso, prefiro usar o termo "materiais" em vez de "materialidade" por entender que este último remete ao hilemorfismo da matéria, encerrando-a no fechamento, na morte, conforme destacou Ingold (2012). Ao considerar as falas de um corpus de análise como materiais, estou tentando pensar no movimento de abertura e de interpretação que ressignifica constantemente as interações linguageiras.
} 


\section{Caatinga, sertão e semiárido}

Após concluir a minha pesquisa de tese, viajei para São Paulo em setembro de 2018. Lá, decidi visitar o museu interativo "Catavento Cultural e Educacional” no Parque Dom Pedro II, Bairro Brás. Naquele Museu, fui surpreendido pela exposição “Biomas do Brasil”. Fiquei algum tempo lendo os textos e as imagens da exposição, estabelecendo relações com as interpretações da minha pesquisa de doutoramento e logo fui capturado pelos agenciamentos do campo etnográfico caatinga-sertão-semiárido, aqui expresso no hibrido sudoeste da Bahia, que me provocaram a pensar nas regularidades dos discursos sobre os biomas brasileiros. Ali, um mapa tátil para deficientes visuais apresentava o bioma caatinga na cor branca. Outro mapa apresentava a caatinga e, em sua descrição textual, constava: “A palavra caatinga vem do Tupi e significa mata branca, devido ao comportamento esbranquiçado dos galhos e das árvores". E, ainda, dividia a caatinga em agreste, "próxima a mata atlântica e com maior umidade", e sertão, "com pouca vegetação e seca".

Nesses termos, caatinga seria, então, um território de pouca vegetação, esbranquiçado e seco (o sertão), sendo que a região de umidade estaria nas cercanias da mata atlântica. Tal entendimento ressoou nos significados que transitaram no campo de pesquisa. Considerando o caráter multidisciplinar das categorias de território, os biólogos ajudaram-me a problematizálas. Eles destacaram que as suas descrições sobre os não humanos e os seus territórios não são produtos estritos dos agrupamentos científicos aos quais se vinculam no tempo presente (botânica e zoologia, por exemplo), mas elaborações que compõem regularidades discursivas (FOUCAULT, 2008) com distintos modos de conhecer de diferentes temporalidades. As descrições dos biólogos, produzidas em vivências concretas, seriam também produtoras de tais regularidades.

Em distintos momentos de interlocução, fui provocado pelos biólogos a retomar os trabalhos de descrição da biodiversidade produzidos pelos naturalistas viajantes. Eles sinalizavam que os trabalhos contemporâneos sobre diversidade e ocorrência de plantas e animais em um determinado território são herdeiros dos trabalhos dos naturalistas e com eles estabelecem regularidade. Um desses trabalhos foi realizado pelo austríaco Maximiliano de Wied-Neuwied ${ }^{9}$ entre 1815 e 1817, em territórios da Bahia. Este austríaco coletou espécimes

\footnotetext{
${ }^{9}$ Através de um dos meus interlocutores, conheci o livro "Viagem ao Brasil", do naturalista austríaco Maximiliano de Wied-Neuwied. Esse interlocutor disse-me: "estude este livro que você vai entender como tudo começou". Outro interlocutor se queixou do desinteresse dos alunos de graduação pelos naturalistas.
} 
na região e produziu descrições da natureza, definindo o sertão em tons sublime e maravilhado. Dentre os territórios visitados por Maximiliano, encontra-se a região ecotonal ${ }^{10}$ onde fica hoje Vitória da Conquista. Essas e outras descrições são consideradas um marco para os estudos etnológicos no Brasil (COSTA, 2008) e corroboram indícios de que o conceito de sertão é também uma invenção dos colonizadores para atender a uma dupla finalidade: classificar o distante e o exótico e distribuir identidades que podem também assumir o sentido de liberdade e paraíso ecológico a depender do lugar de fala (AMADO, 1995).

Os sertões, categoria utilizada para definir territórios em todas as regiões brasileiras, aparecem como protagonistas em relatos de naturalistas e em outras descrições sobre o Brasil, a exemplos da produção literária e da historiografia nacionais. Na Bahia, seus territórios são considerados semiárido e caatinga por muitos dos seus moradores. Semiárido e caatinga são definições que tratam da região nordeste e de um fragmento de Minas Gerais. As áreas nativas mais expressivas de caatinga estão na Bahia e no Piauí (LEAL; TABARELLI; SILVA, 2003).

O Instituto Brasileiro de Geografia e Estatística (IBGE) define a caatinga como um dos seus seis biomas do território nacional (com 9,92\% da sua área) juntamente com amazônia $(49,29 \%)$, cerrado $(23,92 \%)$, pantanal $(1,76 \%)$, pampa $(2,07 \%)$ e mata atlântica $(13,04 \%)$. Mais da metade (54\%) da Bahia é constituída pelo bioma caatinga, sendo que uma parcela significativa do seu território chamada de semiárido (39,8\%) é também território da caatinga. O semiárido é também institucionalizado pelo IBGE como área de semiaridez e pobreza hidrográfica. ${ }^{11}$

\section{A emergência de um endemismo}

Em 2015, estabeleci interlocução com uma bióloga envolvida na descoberta e descrição de uma cactácea endêmica da caatinga: a professora-bióloga Marylan de Oliveira Coêlho ${ }^{12}$.

\footnotetext{
$\boldsymbol{E} \boldsymbol{u}$ : Faço uma pesquisa de doutorado sobre relações entre pessoas, plantas, animais e outros seres descritos pelas ciências biológicas no sudoeste do Estado da Bahia e gostaria de conhecer como as cactáceas foram classificadas, especialmente a planta que foi classificada em sua homenagem, a Arrojadoa marylanae. Você poderia falar um pouco sobre isso?

Marylan: Desde pequena sentia um desejo enorme de subir à Serra Escura, uma montanha presente na fazenda Sete Várzeas, pertencente aos meus avós maternos. Porém, meus pais nunca permitiram. Cresci e, no dia sete de setembro de 2001, estava

${ }^{10}$ Ecótonos são regiões de fronteiras entre dois biomas.

11 Informações disponíveis em: http://www.ibge.gov.br/home/presidencia/noticias/21052004biomashtml.shtm. Acesso em: 08 out. 2015.

${ }^{12}$ Os meus interlocutores autorizaram a identificação dos seus nomes para fins de produção e divulgação de artigos, relatórios e outros trabalhos acadêmicos.
} 
eu fazendo minha segunda graduação, agora em ciências biológicas, quando fiz o convite aos meus amigos e ao professor da UESB, Avaldo Soares, para fazermos uma excursão à Serra com intuito de matar o meu desejo antigo e também fazer um levantamento de flora e fauna daquele espaço. Não existiam trilhas e seguíamos abrindo ao longo do caminho. Tiramos muitas fotos e coletamos amostras da vegetação. O tempo passou muito rápido e escureceu logo. Por isso, algumas amostras ficaram para trás, tínhamos que pular rochas muito altas e com este material ficava difícil. Chegamos à casa após uma exaustiva e maravilhosa excursão. Sonho realizado e um sorriso radiante no rosto. Depois, em casa, em Vitória da Conquista, analisando as fotografias, o professor Avaldo identificou a espécie de cacto que, até então, não tinha sido descrita.

$\boldsymbol{E} \boldsymbol{u}$ : Você poderia falar sobre a sua relação com as plantas nos diferentes espaços e momentos do seu cotidiano?

Marylan: Desde criança, gostava de cultivar plantas ornamentais. Hoje, continuo com o mesmo hábito. Mesmo morando em apartamento, tenho meus cactos, minhas orquídeas, violetas, samambaias. Tinha muito mais, porém tive que reduzir, afinal um apartamento não é uma casa de quintal. Quando cheguei e chego à Serra, fiquei e fico deslumbrada, parece uma magia. Nesta parte, onde moram as Arrojadoas, há uma vegetação fechada embora seja na caatinga. Hoje, com a mineração, trilhas maiores foram abertas, mas na primeira vez não. O encantamento foi tão grande que o tempo passou sem que percebêssemos. A serra é mesmo encantadora. Lá do alto, temos uma visão privilegiada do espaço geográfico da bacia do Rio de Contas. Dá para percebermos a ação humana nestes espaços, tanto as positivas quanto as negativas. Você tem uma sensação de liberdade imensurável. É um dos locais que mais visito em pensamentos porque me traz tranquilidade à alma.

$\boldsymbol{E} u$ : O que você pensa da relação entre cactáceas e as definições de sertão?

Marylan: Não existe sertão sem cactáceas e vice-versa. É o retrato do sertão. Mandacaru, cabeça-de-frade, opuntias, xique-xique, rodantes...

De modo desbravador e aventureiro, Marylan apresentou o território da caatinga que visitou como exceção caraterizada pela presença de "mata fechada" e o sertão e as cactáceas circunscritos um ao outro. O desejo de conhecer a Serra que emergiu na sua infância foi interditado pela família e recolocado em circulação quando ela se tornou estudante de graduação. Ao "matar” o seu desejo em uma expedição, algumas cactáceas tornaram-se visíveis de uma maneira específica ao modo de ver também específico do seu professor. Após coleta e interpretação do material da Serra, uma planta parecia não representar nenhuma espécie já descrita. Esta planta, posteriormente, recebeu o nome "Arrojadoa marylanae Soares Filho \& M.Machado”. Para Marylan, a Serra é um coletivo que ressoa em sua sensação de liberdade e tranquilidade.

Conforme interlocutores do tempo presente e os registros encontrados na primeira expedição, a Serra não se deixou de mostrar exótica e de atrair a atenção de outros pesquisadores, que passaram a visitá-la. A descoberta da Serra para Marylan (descoberta-paraMarylan) ofereceu outras possibilidades de trabalho e de afetos entre humanos e plantas que transbordaram para as residências dos biólogos.

Seguindo o coletivo plantas-biólogos, foi possível rastrear uma cactácea e os pesquisadores envolvidos na sua descrição. A interlocução acima também sinaliza para o 
caráter temporal (histórico) das relações biólogos-biólogos e biólogos-plantas-outros não humanos. $\mathrm{O}$ entendimento do campo exigiu um sentido de história nos termos da formulação de Ingold (2015; 2006): como crescimento de condições de desenvolvimento nas quais os seres humanos operam processos de transformação, fazendo crescer uns aos outros na ação prática de estabelecimento de tais condições para humanos e não humanos. A vida social é, então, entendida aqui como um plano horizontal no qual não se exclui o mundo orgânico (a natureza), o que me levou a rejeitar também a ideia de uma história para os humanos e uma história para os não humanos para compreendê-la como narrativa de coletivos que comportam distintas linhas de movimento em diferentes enredos. Vejamos alguns dos apontamentos dos itinerários dos entes produtores do endemismo da Serra Escura.

Encontrada no município de Tanhaçu, Bahia, “Arrojada marylanae Soares Filho \& M.Machado" é hoje descrita como uma espécie de cactácea endêmica da caatinga brasileira citada na lista vermelha das espécies ameaçadas de extinção da União Internacional para Conservação da Natureza e dos Recursos Naturais (IUCN). A sua classificação como nova espécie foi divulgada no "British Cactus \& Succulent Journal” em 19 de abril de 2003. Ela foi descrita por Avaldo de Oliveira Soares Filho e Marlon Câmara Machado como planta de

\begin{abstract}
Caule robusto, ereto e indiviso provido de cefálios anelares lanosos, pelo elevado número de costelas, pelas aréolas providas de espinhos flexíveis, pelas flores tubulares pequenas com segmentos de perianto pouco espessos, delicados e patentes, e pelos frutos obovoides pequenos com polpa translúcida e aquosa. (SOARES FILHO; MACHADO, 2003, p. 114).
\end{abstract}

Até o final da década de 1990, esta cactácea existia apenas para os seres que habitavam a Serra. Ela passou a existir para os biólogos e para suas comunidades textuais quando o desejo de Marylan (conhecer a Serra Escura) circulou em sua formação. Mas isso não bastou! Foi preciso que a planta fosse capturada pelo modo de ver de Avaldo, que interrogou as taxonomias já produzidas e, posteriormente, a descreveu em parceria com Marlon.

O enunciado "Arrojada marylanae Soares Filho \& M. Machado" 13 é formado pelo verbete "Arrojada", que indica o gênero a que pertence; uma segunda palavra, "marylanae”, usada para homenagear a então discente Marylan; seguida pelos nomes dos seus classificadores, Avaldo de Oliveira Soares Filho e Marlon Câmara Machado. Gênero, neste contexto, é um táxon que agrupa espécies que possuem proximidade filogenética. As espécies que compõem

\footnotetext{
${ }^{13}$ Arrojadoa marylanae, sem as especificações dos determinadores (Avaldo de Oliveira Soares Filho e Marlon Câmara Machado), foi o uso mais comum no campo. Por isso, daqui por diante, mantenho apenas está formulação.
} 
um gênero compartilham muitas características morfológicas e funcionais, porque, em termos evolutivos, possuem ancestrais comuns. A cada endemismo descrito, o gênero é ampliado ou reformulado.

Em taxonomia, a denominação de uma espécie, de um gênero e demais táxons pode estar relacionada a uma homenagem ${ }^{14}$. O gênero "Arrojadoa", no qual se inclui o endemismo de Marylan, Avaldo e Marlon, por exemplo, é uma homenagem de Britton e Rose (1919), botânicos estadunidenses que descreveram o gênero nas duas primeiras décadas do século XX, a Miguel Arrojado Lisboa (1872-1932), engenheiro e geólogo brasileiro que atuou no reconhecimento do traçado da Estrada de Ferro Noroeste do Brasil.

Avaldo é professor do Campus de Vitória da Conquista da UESB desde o final da década de 1980, exercendo também, nesse período, a função de curador de herbário e de coordenador de laboratório. Suas atividades de pesquisa dão ênfase a fitossociologia, conservação e fitogeografia. É graduado em ciências biológicas, mestre em ecologia e doutor em botânica. O outro pesquisador, Marlon Câmara Machado, é taxonomista de cactácea, bacharel em informática, mestre e doutor em botânica. Este personagem possui implicações próprias que sinalizam confluências de linhas em redes de taxonomias que envolvem pesquisadores de diferentes instituições.

Marylan foi aluna da primeira turma de Licenciatura em Ciências Biológicas do Campus de Vitória da Conquista da UESB. Nascida em Vitória da Conquista, foi criada em Sussuarana (Distrito de Tanhaçu, Bahia) e, aos 15 anos, regressou à cidade onde nasceu para estudar e trabalhar. Hoje, é professora da educação básica e ativista em defesa das cactáceas das caatingas. Quando regressou para estudar ciências biológicas em 1999, já tinha formação em Licenciatura Curta em Ciências pela UESB.

Marylan e Avaldo vivem em interação com plantas, as suas residências são habitadas por diferentes tipos delas. As práticas com plantas e das plantas transbordam as fronteiras do trabalho e da vida pessoal e se articulam, de forma permanente, às suas existências. As cactáceas autorizam, concedem, estimulam, sugerem, influenciam, interrompem, possibilitam, proíbem, bloqueiam... pesquisas e outras ações da vida de Marylan e Avaldo, elas são agentes ativos que garantem durabilidade e amplitude das interações (LATOUR, 2012). Participam, dentre outras coisas, de experiências de circunscrições de territórios. E, para retomar os traçados locais da

\footnotetext{
${ }^{14}$ Essas homenagens são pouco investigadas pelos estudos sociais da ciência e são férteis em possibilidades de reflexão das políticas institucionais e relações de empatia que compõem as ciências biológicas.
} 
experiência de descoberta de Arrojadoa marylanae, aceitei o convite de Marylan e fui, com ela, ao encontro da Serra Escura.

\section{Subindo a serra}

Em um desses dias de muita chuva, dias em que a terra molhada exala uma diversidade de cheiros, preparava-me para uma expedição à Serra Escura no distrito de Sussuarana, pertencente ao munícipio de Tanhaçu, Bahia. Com estradas margeadas por diversos e exuberantes tons de verde, vermelhos, amarelos, brancos e outras cores, fiz o deslocamento da cidade de Brumado, que dista 538 quilômetros da capital Salvador, para o distrito de Sussuarana, numa viagem de 53 quilômetros aproximadamente na noite do dia nove de janeiro de 2016, para encontrar com Marylan, que me esperava para refazer a expedição à Serra Escura na manhã do dia seguinte.

Ao chegar ao local, identifiquei a presença de muitos caminhões que realizavam transporte de peças para montagem de torres de parques eólicos, empreendimentos que começavam a se instalar de forma veemente na região. Havia muitos moradores nas ruas, sentados em frente as suas casas, conversando e ouvindo músicas reproduzidas em aparelhos de som de carros. Recebi, por telefone, as informações para chegar ao local onde nos encontraríamos e recorri aos moradores para identificá-lo. Todos eles conheciam Marylan e apontaram a direção da casa da sua família. Sua mãe e seus filhos estavam na casa e fizeram a recepção, informando que Marylan havia saído e que retornaria em breve. Logo, iniciamos uma conversa e a mãe de Marylan detalhou o "envolvimento de uma vida" da sua filha com a Serra e os seus próprios medos acerca daquele lugar. Ela nos contou que nunca havia subido a Serra, mesmo morando parte de sua vida muito próxima dela, na Fazenda Sete Várzeas, devido à possibilidade de encontrar onças e à topografia do terreno ${ }^{15}$.

Marylan chegou algum tempo depois e se juntou à sua família para fazer coro às narrativas de recepção. A conversa seguiu até próximo de meia noite, com destaques para os assuntos que giravam em torno de Arrojadoa marylanae, a primeira expedição à Serra e as suas muitas replicações para levar professores de universidades brasileiras, norte-americanas e europeias. Ela falou dos laços de amizade que teceu com o professor Avaldo e sua família.

\footnotetext{
${ }^{15}$ Há relatos de moradores do distrito que indicam que a Serra Escura é habitada por onças.
} 
A primeira expedição gerou alguma tensão nos familiares dos dois exploradores que ficaram em Sussuarana. Marylan e Avaldo saíram cedo para um lugar desconhecido com o compromisso de regressarem antes do sol se pôr, o que não aconteceu. O pai de Marylan juntouse a outros moradores para tentar encontrá-los. As pessoas do Distrito começaram a aventar a possibilidade da uma onça ter comido os dois, acentuando uma tensa espera por dois humanos que se enveredaram pela Serra para conhecer plantas, animais e territórios das caatingas. Contase que, no momento da saída de várias pessoas para o resgate, Marylan e Avaldo foram vistos regressando para casa. Os humanos de Sussuarana, que jamais tinham visitado a Serra, estavam dispostos a enfrentar seus medos para encontrar dois outros humanos que por ela se "perderam".

A conversa foi interrompida com um convite para a última refeição do dia. $\mathrm{Na}$ sequência, dormimos todos na casa da família, conforme fazem os muitos convidados de Marylan que reproduzem a mesma expedição em busca das cactáceas daquela região da caatinga. Tal acolhimento faz parte de suas práticas de ativismo, que traçam linhas que deslocam o território por meio dos trabalhos desenvolvidos pelos pesquisadores visitantes e divulgados em revistas científicas do Brasil e do exterior.

Na manhã seguinte, levantamos às seis horas da manhã, tomamos café e formamos um grupo com cinco integrantes, a saber: Marylan, seu filho mais velho, sua segunda filha, João Maurício (professor que observava e fotografava a expedição) e eu. Ficaram na casa da família, sua filha mais moça e sua mãe, que jamais subiram a Serra. Marylan tentou se comunicar com um mateiro, pessoa que tem habilidade para se deslocar em matas, mas, sem obter êxito, decidiu "subir a serra" guiando-nos. Nossa anfitriã tornou-se também a nossa mateira.

No percurso feito de carro, da casa ao "pé da serra", encontramos muitas poças d'água e flores brotando entre os espinhos das cactáceas. Paramos o carro para contemplar as paisagens, abrir cercas e conversar com moradores, que eram também parentes de Marylan. Chegamos a um ponto onde seria a "entrada" da Serra e nos deparamos com uma cerca de arame farpado bloqueando a entrada, o que gerou estranhamento em Marylan. Após percorrer outro trecho em busca de um acesso, retornamos à entrada bloqueada pela cerca, descemos e a retiramos para ultrapassar o limite por ela demarcado. Sob a cerca, havia uma pequena ponte feita de pedaços de madeira que pareciam poderes. Marylan pediu para dirigir o carro, até então dirigido por mim, por conhecer melhor o terreno. Seu filho e eu ficamos do lado de fora ajudando na orientação para direcionamento exato dos pneus. O risco de acidente parecia nítido a mim naquele momento. 
Seguimos um pouco mais de carro sobre gramíneas e margeando uma lagoa até chegar a uma casa, pertencente hoje a uma empresa de mineração dona do fragmento da Serra em que adentraríamos. Marylan foi à casa e uma pessoa que lá estava já sabia da nossa visita e autorizou a subida. A anfitriã-mateira havia feito contatos prévios. Seguimos mais um pouco até um limite em que o terreno não permitia a entrada do carro e, a partir daquele ponto, passamos a andar a pé.

Uma revoada verde e amarela de "periquitos da caatinga", que vocalizavam em diferentes direções, nos recepcionou no "pé da serra". O grupo começou a caminhar pela Serra em direção ao seu topo, pelos cenários materiais de caatingas/semiáridos/sertões que esboçavam diversidade de cores e cheiros. A Serra era bem íngreme a ponto de produzir uma impressão em um dos membros da expedição, que a narrou ao final: "parecia um paredão, achei que não conseguiríamos subir".

Orientados por Marylan, levamos água e alguns biscoitos. Ela distribuiu paçocas aos membros do grupo e parava a cada encontro com uma cactácea, apresentando-nos alguma categoria taxonômica que permitia, além do enquadramento do espécime, a narrativa de alguma história a ela relacionada. Ela narrou também episódios de extração na área, revivia expedições anteriores com o professor Avaldo e com outros professores e falava das atividades que desenvolvia nas escolas onde trabalhava. Suas narrativas sobre taxonomias eram narrativas também da sua história de vida, formação e atuação profissional. Cactos, morcegos, onças, periquitos, aves, folhas e flores eram os personagens centrais das falas descritivas sobre a Serra que a encanta desde a infância. Encontramos árvores "carregadas de umbus", os umbuzeiros, que provocaram uma parada na expedição para experimentar o sabor daquela mata.

A expedição seguia quando, já chegando ao topo da Serra, deparamo-nos com um túnel incrustado em rocha, resultado de ações de exploração da mineração e de ações de intemperismo. Marylan pediu que nos aproximássemos da abertura para escutar os sons de morcegos que ali habitavam. Na sequência, seguimos a caminhada. Olhávamos sempre para o alto em busca de qualquer sinal de Arrojadoa marylanae, que estava no pico da Serra Escura.

Chegamos ao pico da Serra Escura após cerca de uma hora de caminhada. Os membros da expedição alternavam-se em momentos de silêncio, observando as plantas, os animais, a composição geológica da Serra e a paisagem que se apresentavam para serem vistos (STRATHERN, 2014), e de diálogo (descrição-interpretação) sobre esses atores e sobre si(nós) mesmos. Ao nosso lado, estavam as instituições universitárias e demais entes que nutriram a circulação dos desejos que provocaram os nossos deslocamentos. Após ficar um tempo no topo 
da Serra Escura, partilhando as condições de existência da Serra, descemos para retomar a vida urbana com novos significados produzidos sobre a relação entre humanos e não humanos que animavam (e reinventavam) os nossos corpos.
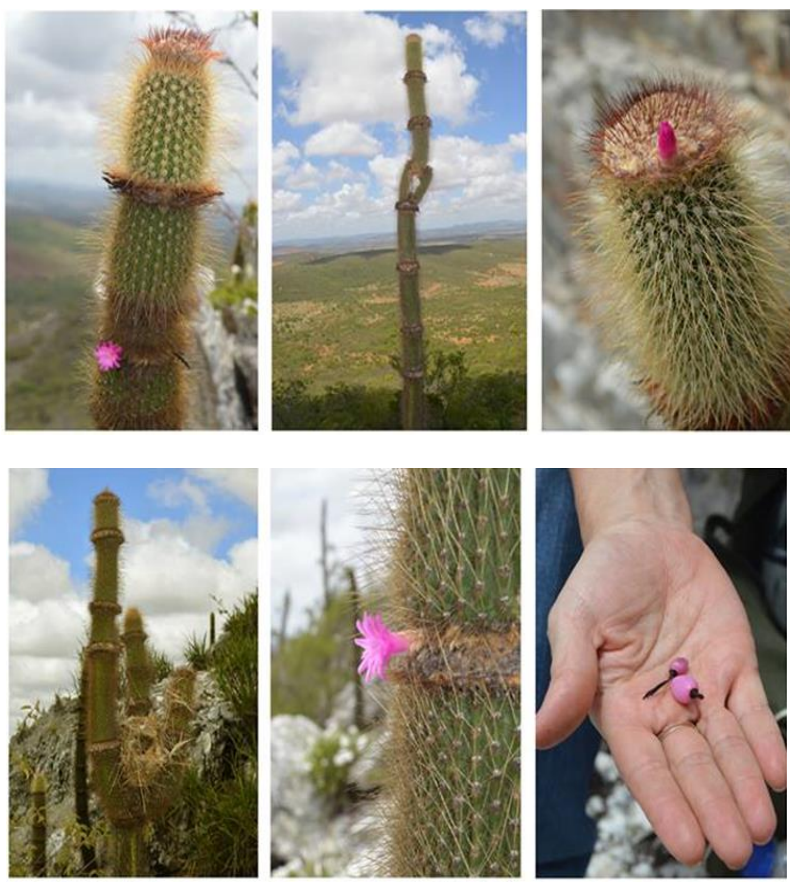

Fotografias 1 - 6 - Arrojadoa marylanae Soares Filho \&

M.Machado. Fonte: Autor

\section{Espécies endêmicas e espécies cosmopolitas em discursos sobre biodiversidade}

Endemismos, como Arrojadoa marylanae, podem estar relacionados a controvérsias em determinados fóruns de reflexão sobre a biodiversidade. Sobre isso, conversei com um perito do Intergovernmental Platform on Biodiversity and Ecosystem Services (IPBES) em 2015. A seguir, transcrevo dois recortes das suas falas relacionados à relação entre endemismo e biodiversidade da caatinga.

Perito: A biodiversidade da caatinga é muito maior do que se pensa, tem até beijaflor endêmico da caatinga, e ao mesmo tempo, você tem uma pressão muito grande pelos recursos naturais nessa região. Eu tenho que pensar se de fato a caatinga tem que ser explorada da maneira e no ritmo que ela está sendo. Nós estamos tendo, principalmente nas regiões mais úmidas, uma exploração muito intensa que pode inclusive levar ao esgotamento de recursos hídricos. Nós precisamos entender a caatinga... A caatinga talvez seja o ambiente mais menosprezado do contexto brasileiro. Quando se falou do tatu mascote da Copa do Mundo [de Futebol] de 2014, o "Fuleco", ninguém falou que ele já tinha entrado na lista de animais ameaçados de extinção. O “eco" que compõe a palavra Fuleco nos remete a proteção. Ou seja, parece que é a espécie mais protegida ou que vive no ambiente mais protegido do país e é exatamente o contrário. 
Perito: Então, você saúda: “nós temos uma espécie endêmica aqui, ai que bom!”. Por quê? Mas as espécies que não são endêmicas, as espécies cosmopolitas? Elas não têm nada a menos, elas não são menos importantes. É importante entender a importância dos endemismos e, ao mesmo tempo, os cosmopolitanismos, o comportamento das espécies não endêmicas. O grande problema hoje, na questão da biodiversidade, é entender a dinâmica local e a dinâmica regional e global. No IPBES, essa é uma das questões. O conceito de "hotspot" de biodiversidade acabou gerando um subproduto que não se esperava, que é uma desvalorização dos outros locais; se conservar o "hotspot", pode-se destruir todo o resto, e não é verdade. O conceito de "hotspot" é um conceito que ajuda a eleger prioridades, mas ele não dispensa a atenção global. Então, hoje eu estou dedicando uma boa parte do meu tempo a discutir como formar recursos humanos para enfrentar a questão da biodiversidade, entendendo a igual importância desses níveis. Há processos globais que, se deixarem de ocorrer, produzem um impacto direto em cadeias alimentares em todo planeta e nos endemismos. Não pode perder de vista essa multidimensionalidade das atenções que a diversidade requer. Você não pode falar assim: "Ah! Esse lagarto aqui endêmico!", "Esse sapo endêmico! Que legal!", "Esse sapo vive em todo lugar!", "Essas aves migratórias!", "Essa..." Entende?

O perito destacou a existência de espécies não endêmicas como parte da composição de biomas, que são também importantes para entender os territórios, sejam eles denominados "hotspot ${ }^{16 "}$ ou não. Endemismos e cosmopolitismos vinculam a biodiversidade do planeta de maneira mais ampla, vinculam o local e o global. Sair da dualidade territórios excepcionais, de um lado, e demais territórios, de outro lado, implica em compreender as plantas e os animais em uma descentralização na qual se ancoram outros entes, humanos ou não. Dessa forma, Arrojadoa marylanae, enquanto planta, não seria apenas um endemismo e a Serra Escura, enquanto território de caatinga, apenas um território ameaçado de destruição, mas também coletivos de plantas, animais, biólogos e outros seres não endêmicos que os tornam possíveis e que também devem ser entendidos como vidas e territórios que importam para a biodiversidade.

A despeito das muitas contribuições que esta interlocução me proporcionou, recortei o fragmento "tem 'até' beija-flor endêmico da caatinga" para explorar a compreensão da biodiversidade da caatinga a partir dos discursos que o antecedem, estando estes disponível para a construção daquele. O enunciado em tela parece estabelecer regularidade com falas dos meus interlocutores ao longo do trabalho de campo, como, por exemplo, a referência que Marylan fez a Serra Escura: "há uma vegetação fechada 'embora' seja na caatinga”.

Nesses recortes, as preposições "até" e "embora" funcionariam como artifício para incluir "beija-flor" e "mata fechada" na caatinga, enriquecendo-a em sua "pobreza". No entanto, ao reunir as falas de Marylan e do Perito com as de outros biólogos com quem

\footnotetext{
16 "Hotspot de biodiversidade" define regiões biogeográficas de alta diversidade, com vegetação diferenciada (com endemismos excepcionais) e ameaçada de destruição.
} 
estabeleci interlocução, é possível sustentar que tal "pobreza" não se refere necessariamente à caatinga enquanto bioma (a natureza como um dado, uma pura exterioridade), mas aos discursos a ele relacionados. Os interlocutores estariam, então, alertando-nos para um olhar mais atento para os entes a fim de enriquecer nossos discursos sobre a biodiversidade deste bioma na formação da ideia de nação rica em biodiversidade. Torna-se possível afirmar que um dos sentidos possíveis se assenta em um silenciamento acerca da biodiversidade do bioma caatinga. Silenciamento aqui entendido como uma rarefação do argumento para tornar possível um dizer na ausência de outras possibilidades de enunciação (ORLANDI, 2007).

As elaborações sobre o descentramento do sujeito, fugindo do seu oposto produtor e dominador dos conteúdos dos seus discursos, como ponto de partida e de chegada do sentido, são aqui ampliadas para compreender as elaborações sobre as agências dos não humanos como importantes para a compreensão da ação. Para entender o indivíduo como multidão (TARDE, 2007), os não humanos como agentes (LATOUR, 2012) e as existências em campos relacionais (INGOLD, 2015), precisamos de formulações interpretativas que, no mínimo, considerem a possibilidade de existência de comunicação entre os diferentes entes (humanos ou não), vinculados em relações transespecíficas, todos eles compreendidos como significados e significantes.

Circunscrever Arrojadoa marylanae à Serra Escura é apenas uma maneira de marcar um registro da sua existência, o que não significa encerrá-la naquele território. Significa que as expedições dos biólogos a encontraram naquele lugar, por ora. Em um determinado momento da pesquisa da qual este texto é um desdobramento, ouvi um biólogo dizer que, em algumas situações, é possível encontrar uma espécie endêmica circunscrita a um território especifico, mas, com a sequência do trabalho, com a "exploração" de outras áreas, descobre-se que aquela espécie habita também em outros territórios, inclusive bem distantes (biomas diferentes). Feita esta "descoberta", a espécie ou grupo considerado endêmico até então perde este estatuto e se torna cosmopolita para os biólogos e para as suas comunidades textuais.

Arrojadoa marylanae é uma história que agrega outros seres. Os movimentos que produziram a sua primeira descrição também a deslocaram para outros territórios. Ela é o seu movimento, como é o biólogo. Aqui é possível problematizar a crítica de Ingold (2015) às taxonomias, chamando-as de conhecimento vertical e sem história. Isso pode ser plausível se considerarmos as definições em livros e outros compêndios que trazem mapas simplificadores, como os cladogramas, diagramas que indica as relações entre táxons. Porém, quando ouvimos 
um biólogo e observamos as suas ações, somos surpreendidos por narrativas que as taxonomias dos livros não alcançam. Isto também não seria taxonomia para além do conhecimento vertical?

Diferenças morfológicas da cactácea de Marylan mostraram-se visíveis aos modos de ver dos biólogos, especialmente de Avaldo, foram marcadas com um nome, uma distinção, Arrojada marylanae, e posicionada em um grupo de plantas que são próximas filogeneticamente, a Família Cactaceae. Assim, Arrojadoa marylanae foi situada no Gênero Arrojadoa da Família Cactaceae. Ao retomar o diálogo com os biólogos que descreveram a planta, pude identificar que uma taxonomia pode ser também uma forma de contar a história da planta, dos seres e dos territórios que com ela se agregam, o que me permitiu questionar: quais histórias podem ser contadas quando retomamos uma descrição sobre da biodiversidade? Se considerarmos que a vida é tecida em relação e se existirem sempre movimentos de agregação de seres, a história seria então um movimento de retomada das muitas histórias das relações de forma que descrições são sempre narrativas de coletivos que comportam continuidades e rupturas. Taxonomias são aqui, simultaneamente, classificações e histórias; um movimento de constante produção de diferença.

\section{Considerações finais}

Coleta de plantas realizadas por biólogos em um determinado território não significa subtração de frações que o constitui, mas o seu prolongamento para outro local onde ele é transformado/traduzido. Estas plantas, descritas e posicionadas em táxons mais abrangentes, como gênero e família, compõem um quadro de significados historicamente produzidos, que são mobilizados, interpretados e reinterpretados em contextos de formação e trabalho da taxonomia vegetal. Coleta de plantas em um território e o trabalho de tradução destes não humanos em laboratórios e herbários produzem registros de ocorrência que indicam a existência de espécies já encontradas em outros lugares, as plantas cosmopolitas, e espécies jamais encontrados em outros territórios, as plantas endêmicas.

Biólogos entendem que os interesses por endemismos não podem desconsiderar a importância das espécies não endêmicas como parte das descrições da biodiversidade e, tampouco, construir imaginário de proteção às espécies ameaçadas apenas quando estas são endêmicas. As espécies não endêmicas permitem identificar a imbricação e o vazamento (INGOLD, 2012) dos territórios exatamente onde os endemismos esbarram em suas circunscrições. Segundo eles, tais espécies dizem muito sobre adaptação: distribuem de maneira 
cosmopolita, porque apresentam variações que permitem enfrentar os desafios dos diversos ambientes. Não são melhores nem piores do que as plantas endêmicas, são plantas boas para viver dispersas pelos diversos territórios.

Enviei recortes do meu caderno de campo para uma pesquisadora que viveu em um herbário durante alguns anos da sua vida. Queria saber dela se as minhas interpretações ressoavam naquilo que ela viu e ouviu sobre a relação entre biólogos e plantas. Dentre outras coisas, ela ponderou:

Pesquisadora: As relações de fato elas são muito estreitas com as plantas e os animais que os taxonomistas estudam, a ponto de chamarem plantas e animais de bebês, de amores, de meus filhos e de minhas filhas. Então, aquela coisa do taxonomista passar muito tempo com um objeto de trabalho e o transformar em ente querido mesmo, porque esses exercícios de nomeação taxonômicos te colocam para conhecer mesmo aquilo ali como se fosse, de fato, um filho. A planta e o animal são como filhos, que o pai ou a mãe vão dar o nome ao filho, ou que deram o nome; ou, no caso de biologia, que vão dar. Tem que conhecer, né? Tem que desmembrar para poder reunir esses pedacinhos em um nome, mesmo que seja em outros pedacinhos depois. Essas relações, de fato, são muito estreitas. Quando um nome é dado a uma espécie, discursivamente significa, para quem conhece os passos para se nomear uma espécie, todo processo até chegar a um nome. O nome final, ele diz respeito ao tempo e à persistência dessa relação do taxonomista com a planta. E essa relação entre nome, discurso e afeto é tão forte que os taxonomistas fazem homenagens aos seus entes queridos.

Em suas palavras, o estreitamento das relações e a elaboração de empatia exigem "tempo" e "persistência". O que dizer de biólogos que se formaram em cursos de graduação, mestrado e doutorado, investigando um grupo ou uma espécie durante cerca de dez anos, e continuaram a pesquisá-lo durante as suas carreiras como pesquisadores? Destaco que "tempo" e "persistência" estão relacionados às especificidades das relações entre biólogos e plantas em florestas, fazendas e matas e entre biólogos e entre biólogos e plantas em laboratórios, herbários e residências. Distinguir os contextos de interação permite investigar singularidades que apontam para os mundos-próprios (UEXKÜLL 1959) de cada espécime ou espécie para entender as agendas dos não humanos, suas disponibilidade e adesões a diferentes interações, que fazem diferença em uma pesquisa nas ciências biológicas.

Ao focar em contextos de relação de plantas e biólogos, foi possível entender a taxonomia de Arrojadoa marylanae como construção relacional, classificação e história e o social como modo de associação em fluxos de desejo (TARDE, 2007). Desejo que emergiu impulsionando humanos a superarem seus medos e subirem em uma serra para experimentar "uma sensação de liberdade imensurável" que se desdobrou em encontros de empatia, 
registrados na descrição de uma planta, que conecta a caatinga às narrativas sobre a biodiversidade do planeta, tornando explícitas as conexões entre local e global.

Os biólogos que pesquisam $a$ e na caatinga, que produzem taxonomias locais, rompem invisibilidades e produzem os territórios (biomas, herbários e outros), as plantas e a si mesmos enquanto existências transespecíficas situadas regionalmente em discursos sobre a biodiversidade mundial. Caminhando por territórios, conversando com mateiros (e outros moradores) e atentos às agendas das plantas com as quais estabelecem relações estreitas, eles produzem diferenças, descrevendo entes situados em pesquisas que almejam à proteção da biodiversidade regional. Penso que, ao assim fazerem, os biólogos se envolvem em práticas de produção do conhecimento que colocam lado a lado os saberes locais, eles mesmos como produções híbridas de biólogos e moradores dos territórios onde produzem coletas, e os saberes globais.

Nessa perspectiva, a categoria cosmopolitismo, proposta por um dos meus interlocutores para fazer referência às plantas e aos animais não endêmicos, permitiria a inclusão de existências secundarizadas na descrição da biodiversidade de um território. No caso das plantas cosmopolitas da caatinga, haveria uma dupla inclusão: das espécies de plantas não endêmicas e do bioma caatinga como parte da biodiversidade brasileira ao qual Arrojadoa marylanae está circunscrita. Ao atuarem dessa forma, os biólogos contribuem para fazer aparecer uma epistemologia da caatinga enquanto bioma eminentemente brasileiro, marcando a Bahia também como diferença. Abre-se, assim, espaço para diversidades epistemológicas que ressoam na formulação de Santos (2007) sobre "ecologia de saberes", aquela que implica uma renúncia de uma epistemologia geral.

A existência de híbridos como movimento de produção de diferenças livra-nos do fardo de essências como puro em si e explicitam a complexidade de um mundo povoado por multidões que se arranjam constantemente em conjunturas espaço-temporais. Nas caatingas dos biólogos, a existência de entes, humanos ou não, permite negar qualquer tentativa de constância material e atemporal de plantas, caatingas e biólogos, tampouco em seus significados. No caso aqui etnografado, o que existe é Arrojadoa marylanae como cactácea de Marylan, Avaldo e Marlon, em modos de ver específicos, que, ao emergir em um significado situado no quadro geral da taxonomia, tornou-se cactácea das caatingas e da biodiversidade do planeta. O que existe são movimentos relacionais de produção de diferenças em coletivos situantes de híbridos. 


\section{Referências}

AMADO, Janaína. Região, sertão, nação. Estudos Históricos, Rio de Janeiro, v. 8, nº 15, p. 145-151, 1995. ISSN 2178-1494. Disponível em: http://bibliotecadigital.fgv.br/ojs/index.php/reh/article/viewFile/1990/1129. Acesso: 10 dez. 2017.

BERGER, John. Modos de ver. Barcelona/ES: Editorial Gustavo Gili, SL, 2000

BRITTON, Nathaniel Lord; ROSE, Joseph Nelson. The Cactaceae: descriptions and illustrations of plants of the cactus family. The Carnegie Institution o Washington: Washington, 1919.

COSTA, Christina Rostworowski. O Príncipe Maximiliano de Wied-Neuwied e a sua Viagem ao Brasil (1815-1817). 140 f. il. 2008. Dissertação (Mestrado em História Social) - Faculdade de Filosofia, Letras e Ciências Humanas, Universidade de São Paulo, 2008.

FOUCAULT, Michel. Arqueologia do Saber. Rio de Janeiro: Forense Universitária, 2008.

GEERTZ, Clifford. Interpretações das Culturas. Rio de Janeiro: Zahar, 1978.

INGOLD, Tim. Estar Vivo: ensaios sobre movimento, conhecimento e descrição. Petrópolis, RJ: Vozes, 2015.

INGOLD, Tim. Trazendo as coisas de volta à vida: emaranhados criativos num mundo de materiais. Horiz. antropol., Porto Alegre, v. 18, n. 37, p.25-44, June 2012. ISSN 01047183. Disponível em: http://www.scielo.br/scielo.php?script=sci_arttext\&pid=S010471832012000100002\&lng=en\&nrm=iso. Acesso em: 13 jan. 2015.

INGOLD, Tim. Sobre a distinção entre evolução e história. Revista Antropolítica, n. 20, p. 17-36, 1 sem. 2006. Disponível em: https://dokumen.tips/documents/sobre-ingold-t-adistincao-entre-evolucao-e-historia.html. Acesso em: 15 mai. 2014.

LATOUR, Bruno. Jamais fomos modernos. São Paulo: Editora 34, 2013.

LATOUR, Bruno. Reagregando o social: uma introdução à Teoria do Ator-Rede. Salvador: Edufba; São Paulo, Edusc, 2012.

LATOUR, Bruno. Ciência em ação: como seguir cientistas e engenheiros sociedade afora. São Paulo: Ed. Unesp, 2011.

LAW, John; MOL, Annemarie. El actor actuado: la oveja de la Cumbria em 2001. Política y sociedad, v. 45, n. 3, p. 75-92, 2009. ISSN 1130-8001. Disponível em: http://revistas.ucm.es/cps/11308001/articulos/POSO0808330075A.PDF. Acesso em: 26 de dez. 2016.

LEAL, Inara; TABARELLI, Marcelo; SILVA, José Maria Cardoso, 2003, Ecologia e Conservação da Caatinga. Recife, Ed. Universitária da UFPE. 
ORLANDI, Eni Pulcinelli. As formas do silêncio - No movimento dos sentidos. Campinas, SP: Editora da Unicamp, 2007.

PERROTA, Ana Paula. Ciência e política no ativismo em favor dos direitos animais. Vivência: Revista de Antropologia, v. 1, n. 49, p. 34-47, 9 out. 2017. ISSN 01043064. Disponível em: https://periodicos.ufrn.br/vivencia/article/view/12796. Acesso em: 07 abr. 2018.

SÁ, Guilherme José Silva e. 'Afinal, você é um homem ou é um rato?'. Campos - Revista de Antropologia, [S.1.], v. 14, n. 1/2, dez. 2013. ISSN 2317-6830. Disponível em:

<https://revistas.ufpr.br/campos/article/view/37272> . Acesso em: 04 jun. 2018.

SANTOS, Boaventura de Sousa. Para além do pensamento abissal: das linhas globais a uma ecologia de saberes. Novos estud. - CEBRAP, São Paulo, n. 79, p. 71-94, Nov. 2007. ISSN 1980-5403. Disponível em: http://www.scielo.br/scielo.php?script=sci_arttext\&pid=S010133002007000300004\&lng=en\&nrm=iso. Acesso em: 28 dez. 2018.

SCHOBER, Juliana. Preservação e uso racional do único bioma exclusivamente nacional. Cienc. Cult., São Paulo, v. 54, n. 2, p. 06-07, Oct. 2002 . ISSN 2317-6660. Disponível em: http://cienciaecultura.bvs.br/scielo.php?script=sci_arttext\&pid=S000967252002000200003\&lng=en\&nrm=iso. Acesso em: 20 fe. 2012.

SEGATA, Jean Gatos fidalgos, cálculos renais e as humanidades dos animais de estimação. Vivência: Revista de Antropologia, v. 1, n. 44, p. 85-104, 24 abr. 2015. ISSN 0104-3064. Disponível em: https://periodicos.ufrn.br/vivencia/article/view/7025. Acesso em: 07 de abr. 2018.

SOARES FILHO, Avaldo de Oliveira; MACHADO, Marlon. Arrojadoa marylanae - a new Arrojadoa species from the state of Bahia, Brazil. British Cactus \& Succulent Journal, v. 21, n 3, 2003. ISSN 0264-3405. Disponível em:

https://www.jstor.org/stable/42793893?seq=1\#page_scan_tab_contents. Acesso em: 20 fev. 2012.

SOUZA, Iara Maria de Almeida. Afeto entre humanos e animais não humanos no biotério. Rev. bras. Ci. Soc., São Paulo, v. 32, n. 94, p. 01-21, 2017. ISSN 1806-9053. Disponível em: http://www.scielo.br/scielo.php?script=sci_arttext\&pid=S010269092017000200504\&lng=en\&nrm=iso. Acesso em: 26 out. 2017.

STRATHERN, Marilyn. O efeito etnográfico. In: STRATHERN, Marilyn, O efeito etnográfico. São Paulo: Cosac Naify, 2014.

SÜSSEKIND, Felipe. O rastro da onça. Rio de Janeiro: 7 Letras, 2014.

TARDE, Gabriel. Monadologia e sociologia: e outros ensaios. São Paulo, Cosac Naif, 2007,.

UEXKÜLL, Jakob Von. Dos animais e dos homens: digressões pelos seus próprios mundos. Doutrina do Significado. Lisboa, Livros do Brasil, 1959. 